\title{
A New Solution to Profit Based Unit Commitment Problem Considering PEVs/BEVs and Renewable Energy Sources
}

\author{
Ayani $\mathrm{Nandi}^{1}$ and Vikram Kumar Kamboj ${ }^{2, *}$ \\ ${ }^{1}$ Power System, School of Electronics and Electrical Engineering, Lovely Professional University, Punjab, INDIA \\ ${ }^{2}$ Power System, School of Electronics and Electrical Engineering, Lovely Professional University, Punjab, INDIA
}

\begin{abstract}
Daily load demand for industrial, residential and commercial sectors are changing day by day. Also, inclusion of e-mobility has totally effected the operations of realistic power sector. Hence, to meet this time varying load demand with minimum production cost is very challenging. The proposed research work focuses on the mathematical formulation of profit based unit commitment problem of realistic power system considering the impact of battery electric vehicles, hybrid electric vehicles and plug in electric vehicles and its solution using Intensify Harris Hawks Optimizer (IHHO). The coordination of plants with each other is named as Unit commitment of plants in which the most economical patterns of the generating station is taken so as to gain low production cost with higher reliability. But with the increase in industrialization has affected the environment badly so to maintain the balance between the generation and environment a new thinking of generating low cost power with high reliability by causing less harm to environment i.e. less emission of flue gases is adopted by considering renewable energy sources.
\end{abstract}

Keywords: BEVs, HEVs, Profit Based Unit Commitment Problem.

\section{Introduction:}

In the modern power sector it is important to gain optimal scheduling to solve profit based unit commitment problem as the actual objective is associated with minimization of cost due to increase in fuel prices as well as maximize with profit. Also, the complication of conventional profit based unit commitment problem has increased due to discharging and charging behaviour of PEV. To minimize the environmental pollution and economic cost, the execution of smart grid need more tools for computation with faster improvement of generation of renewable energy sources, PEVs and further modified electricity storages in power system. The ever-rising interest for vitality has driven experts to pay special mind to inexhaustible wellsprings of vitality and with its developing impact. An unnatural weather change, corruption of the environment and nature of air requires genuine game plan [12]. More work should be done right now. Motivated by these research challenges, intend of the suggested research is to develop a hybrid metaheuristics research algorithm for the solution of PBUCP of electrical power sector considering power demand of renewable energy source and plug-in charging vehicles [15] [16].

\section{Review of Literature}

Profit based unit commitment and economic dispatch effort pair in power generation industry to empower grid management and power generation [13] [14], along these lines adding to a system's general unwavering quality. Be that as it may, the expanding utilization of renewable power generation sources, (for example, solar based and wind based power) is adding uncommon measures of vulnerability to a system operator's power generation scheduling and grid management. The clog of transmission halls because of wind power is getting less surprising since locales with the best wind power potential are regularly situated a long way from load focuses [19] [20]. The stochastic idea of wind modifies the unit responsibility and dispatch issue [21]. By and large, diminish anticipated expenses. One of the errands of the unit commitment problem is to envision this circumstance and execute preventive and remedial control activities by submitting suitable reserve margins or by planning wind power shortening [22] [23] .

Table 1. Literature survey of Profit Based Unit Commitment considering Solar and Wind Power Uncertainty with impact of $\mathrm{BEV} / \mathrm{PEVs}$

\begin{tabular}{|c|c|c|}
\hline Reference & $\begin{array}{c}\text { Year of } \\
\text { Publication }\end{array}$ & $\begin{array}{c}\text { Main findings to proposed } \\
\text { research work }\end{array}$ \\
\hline$[1]$ & 2019 & $\begin{array}{c}\text { The effectiveness of Binary } \\
\text { Differential Evolution algorithm } \\
\text { had been verified on PBUCP }\end{array}$ \\
\hline
\end{tabular}

\footnotetext{
*Corresponding author: vikram.23687@1pu.co.in
} 


\begin{tabular}{|c|c|c|}
\hline & & $\begin{array}{l}\text { system with } 10 \text { gen unit, } 40 \text { gen } \\
\text { unit and } 100 \text { gen unit over the } \\
\text { time schedule. }\end{array}$ \\
\hline [2] & 2019 & $\begin{array}{l}\text { Hybrid GWO and Random } \\
\text { Exploratory Search (RES) } \\
\text { technique had been useful for } \\
\text { PBUCP. }\end{array}$ \\
\hline [3] & 2018 & $\begin{array}{c}\text { Another philosophy was } \\
\text { developed to solve PBUCP } \\
\text { using optimization method } \\
\text { dependent on whale (binary) to } \\
\text { acquire the outcomes as parallel } \\
\text { in environment of PBUC } \\
\text { Problem. }\end{array}$ \\
\hline [4] & 2018 & $\begin{array}{l}\text { Right now output including } \\
\text { arrangement quality and } \\
\text { consistency were contrasted and } \\
\text { other approached utilizing } \\
\text { constrained optimization and } \\
\text { environment roused } \\
\text { optimization. }\end{array}$ \\
\hline [5] & 2018 & $\begin{array}{l}\text { The arrangement superiority } \\
\text { from the research was taken } \\
\text { thought for choose the position } \\
\text { of commitment scheduling and } \\
\text { cause profit to develop by } \\
\text { GENCOs. }\end{array}$ \\
\hline [6] & 2015 & $\begin{array}{l}\text { This methodology was intended } \\
\text { to discover the greatest benefit } \\
\text { in power advertise about how } \\
\text { much power must be taken in } \\
\text { available to be purchased and } \\
\text { save }\end{array}$ \\
\hline [7] & 2015 & $\begin{array}{l}\text { This method was actualized an } \\
\text { IBM PC through which in a } \\
\text { sensible timespan an enormous } \\
\text { sorts of framework can be } \\
\text { continue }\end{array}$ \\
\hline [8] & 2015 & $\begin{array}{l}\text { This paper fundamentally } \\
\text { examined about rapidly begin } \\
\text { and moderate unit utilizing some } \\
\text { essential limitations which helps } \\
\text { in Power Scheduling and } \\
\text { represent to the progression for } \\
\text { plan for vitality to leads } \\
\text { unreachable conveyance of } \\
\text { electrical framework }\end{array}$ \\
\hline [9] & 2018 & $\begin{array}{l}\text { Optimum scheduling for unit } \\
\text { commitment problem } \\
\text { considering photovoltaic } \\
\text { insecurity and suitable power of } \\
\text { EVs and output showed the } \\
\text { reduction of production cost and } \\
\text { improved load flow. }\end{array}$ \\
\hline [10] & 2018 & $\begin{array}{c}\text { Priority-based method was } \\
\text { designed to solve stochastic } \\
\text { UCP considering parking lot } \\
\text { cooperation and renewable } \\
\text { energy sources }\end{array}$ \\
\hline [11] & 2018 & $\begin{array}{l}\text { Dynamic programming } \\
\text { technique was used to discover } \\
\text { realistic conditions of power } \\
\text { generating units, while } \\
\text { consecutive quadratic } \\
\text { programming algorithm was } \\
\text { applied for ELD of committed } \\
\text { gen. units }\end{array}$ \\
\hline
\end{tabular}

Now a days, in power sector, there are different kinds of electric power generating stations like nuclear, thermal and hydro power plants etc [17] [18]. During a day, the demand of electric power is changing continuously and achieves various peak values.

\section{Equations and mathematics}

The generating power is distributed along with utilities of generator scheduling which will meet the time varying load demand for a specific time period is known as Unit Commitment Problem (UCP). The actual objectives of UCP is minimization of overall cost for production considering different system constraints. The overall cost of production including sum of shutdown cost $\&$ start-up cost, cost of fuel are given below:

$$
\min (T F C)=\sum_{h=1}^{H} \sum_{i=1}^{N G}\left\{F_{\cosh i}\left(P_{h i}\right)+S U C_{h i}+S D C_{h i}\right\}
$$

The total cost of fuel over the scheduled time span ' $\mathrm{h}$ ',

$$
\begin{gathered}
T F C=\sum_{h=1}^{H} \sum_{i=1}^{N G}\left[F_{\cosh i} \times U_{h i}+S U C_{h i}\left(1-U_{i,(h-1)}\right) \times \mathrm{U}_{h i}\right] \\
T F C=\sum_{h=1}^{H} \sum_{i=1}^{N G}\left[\left(A_{i} P_{i}^{2}+B_{i} P_{i}+C_{i}\right) \times U_{i, h}+S U C_{i, h}\left(1-U_{i,(h-1)}\right) \times \mathrm{U}_{i, h}\right]
\end{gathered}
$$

Here, cost for fuel $F_{\text {cosih }}\left(P_{i h}\right)$ is stated as quadratic design that mostly working by researchers, also named as equation of convex function.

For the cost of fuel of (n) unit at (t) hour can be mathematically represented as such an equation which is given below:

$$
F_{\text {cosih }}\left(P_{i}\right)=A_{i} P_{i}^{2}+B_{i} P_{i}+C_{i}
$$

$$
\text { Where } A_{i} B_{i} \text { and } C_{i} \text { are represented as coefficients }
$$
of cost that may expressed as $\$ / h, \$ / M W h$, and. $\$ / M W h^{2}$ correspondingly.

Start-up cost can mathematically represented by step function which is given below:

$$
\begin{aligned}
& S U C_{i h}==\left\{\begin{array}{lll}
H S U_{i} ; & \text { for } & T_{i}^{D W} \leq T_{i}^{U P} \leq\left(T_{i}^{D W}+T_{i}^{C O L D}\right) \\
C S U_{i} ; & \text { for } & T_{i}^{U P}>\left(T_{i}^{D W}+T_{i}^{C O L D}\right)
\end{array}\right. \\
& (i \in N U \quad ; \quad h=1,2,3, \ldots, H)
\end{aligned}
$$

In usual value of the Shutdown cost for standard system is denoted as zero and this can be established as fixed cost folowed by the equation number (5).

$$
\mathrm{SDC}_{i h}=\mathrm{KP}_{i h}
$$

Where $\mathrm{K}$ is represented as incremental cost for shutdown.

Which is subjected through some constraints followed by: (1) System constraints and (2) Unit constraints 
$F_{\text {cosh } i}\left(P_{h i}\right)=$ Cost of Fuel for a particular generating unit $\mathrm{i}^{\text {th }}$ at that particular time ' $h$ ' hour $S U C_{i h}=$ Cost of Start-up for $i^{\text {th }}$ unit within' $h$ ' hours

$S D C_{i h}=$ Cost of Shutdown for $\mathrm{i}^{\text {th }}$ unit within' $\mathrm{h}$ ' hours

$S R_{h}=$ Spinning reserve necessity

$P_{h i}^{M A X}=$ Maximum electrical power generation by unit $\mathrm{i}$

$P_{i}^{M I N}=$ Minimum electrical power which generation by unit $\mathrm{i}$

$P_{i, h}=$ Electrical power generation of unit $\mathrm{i}^{\text {th }}$ at the time span' $h$ '

$P D_{h}=$ Load Demand at' $h$ ' hours

$\mathrm{INSi}=$ Initial status of unit $\mathrm{n}$ at time ' $\mathrm{h}$ '

$T_{i, h}^{O F F}=$ Initial OFF status for nth unit at time' $\mathrm{h}$ '

$T_{i, h}^{O N}=$ Initial ON status for nth unit at time' $h$ '

$T_{i}^{U P}=\mathrm{UP}$ condition for i no. of power generating

unit

$T_{i}^{D W}$

generating unit

$\mathrm{T}_{\mathrm{i}}{ }^{\mathrm{COLD}}=$ Time span for COLD start of $\mathrm{i}$ no. of generating unit

$\mathrm{Np}=$ Population Number

$\mathrm{h}=$ No. of hours

$N U=$ No. of generators

$P_{h}^{\text {Re newable }}$

$=$ Power generation

considering

renewable energy source at time ' $h$ '

$D_{h}^{E V S / B E V S}$

$=$ Power demand considering the impact of BEVs/EVs at time 'h'

Constraints for System

System constrains are interrelated with all generating unit existing in the systems. The systems constrains are characterised into two types like:

Power Balance or Load Balance Constraints

In power system the constraint including power balance or load balance is more important parameter consist of summation of whole committed generating unit at $t^{\text {th }}$ time span must be larger than or equivalent to the power demand for the particular time span ' $\mathrm{t}$ '

$$
\sum_{i=1}^{N U} P_{i, h} \times U_{i, h}=P D_{i}
$$

Spinning Reserve (SR) Constraints
Reliability of the system can be considered as facility of extra capability of power generation that is more important to deed instantly when failure is occurred due to sudden change in load demand for such power generating unit which is already running. The extra capability of power generation is recognized as Spinning Reserve which is exactly represented as:

$$
\sum_{i=1}^{N U} P_{i, h}^{M A X} \times U_{i, h} \geq P D_{h}+S R_{h} .
$$

$$
\begin{aligned}
& \text { Step 1: Sort the generators in descending order of maximum generating capacity } \\
& \text { Step2: for } \mathrm{g}=1 \text { to } \mathrm{G} \\
& \text { if } u_{g, h}=0 \\
& \text { then } u_{g, h}=1 \\
& \text { else if } T_{g, h}^{O F F}>M D T_{g} \\
& \text { then } T_{g h}^{O N}=T_{g, h-1}^{O N}+1 \\
& \text { and } T_{g, h}^{O F F}=0
\end{aligned}
$$

Fig. 1. PSEUDO code of SR repairing

Constraints for Power Generating Unit

The specific constraints related with particular power generating unit exist in the systems are called generating unit constraint which are given as:

Thermal unit constraints

Thermal power units are controlled manually. This types of unit need to undertake the change of temperature gradually. So it take certain time span to take the generating unit accessible. So some crew members are essential to execute the maintenance and procedure of some thermal power generating units.

Minimum up Time

This constraint is defined as here will be minimum period of time previously the unit can be start over when the unit have already been shut down which is mathematically defined as:

$$
T_{i, h}^{O N} \geq T_{i}^{U P}
$$

Where, $T_{i, h}^{O N}$ is defined as interval through which the generating unit $\mathrm{i}$ is constantly $\mathrm{ON}$ (in hours) and $T_{i}^{U P}$ is defined as minimum up time (in hours) for the generating unit $n$.

Minimum down Time

When the power generating units will be DE-committed, there is required least period of time for recommitted of the unit which is mathematically given as: 


$$
T_{i, h}^{O F F} \geq T_{i}^{D W}
$$

Where, $T_{i, h}^{O F F}$ is time period for which generating unit $\mathrm{n}$ is constantly OFF (in hrs) and $T_{i}^{D W}$ is denoted as minimum down time (in hours) for the unit.

To adequate minimum downtime and up time repair by heuristic mechanism is accepted those stages are stated as below in Fig. 2.

$$
\begin{aligned}
& \text { for } h=1 \text { to } \mathrm{H} \\
& \mid \begin{array}{l}
\text { if } \mathrm{h}==1 \\
\text { Compute } T_{h}^{O N}=T_{h}^{O N} U_{h i}+U_{h i}{ }^{O N}
\end{array} \\
& \text { Combute } T_{h}^{O F F}=\left(T_{h_{h}}^{O F F}\right)^{\prime} \bar{T}_{h}^{Q N}+\bar{T}_{h}^{Q N} \\
& \text { else } \\
& \text { Compute } T_{h}^{O N}=T_{h-1}^{O N} U_{h i}{ }^{\prime}+U_{h i}{ }^{\prime} \\
& \text { Compute } T_{h}^{\text {OFF }}=T_{h=1}^{\text {OFF }} \bar{T}_{h}^{a N}+\bar{T}_{h}^{a N} \\
& \text { end } \\
& \text { end }
\end{aligned}
$$

Fig. 2. PSEUDO code for MUD/MUT constraints

Max and Min Electric Power Generating Limits

All electricity generating unit have its individual max/ min electric power generating limit, below and outside which will cannot produce and this is known as maximum and minimum power limits, which is mathematically written as:

$$
P_{i}^{M I N} \leq P_{i, h} \leq P_{i}^{M A X}
$$

Initial Status for operation of electrical units

For every units have initial operating position that must proceeds as the day's earlier generation scheduled are taken into consideration, thus each and all generating units can fulfils its lowest down/up time.

Crew Constraint

When any power plant consist of added one units and they couldn't turn on at the same time period. So here need more than one crew members to attend such units in a same time while starting up.

Unit Accessibility Constraint

For the constraint shows accessibility of power generating unit surrounded by any of the resulting various circumstances:

A) Accessible or Non Accessible

B) Must Outage or Out

C) Must running condition

Initial Status of Electricity Generation Unit

It signifies value of initial grade of power generating unit. Its favorable rate signifies the position of current generating unit which already in up condition, which mean about numeral time periods of the generating units are previously up, and for its negative value which is an index of the integer of hour then power generating unit has been previously in down condition. For the position of generating unit $+/$ - earlier the 1 st hour through the schedule which is an essential feature to define where its newest situation interrupts the constraint of $T_{i}^{U P} \& T_{i}^{D W}$.

By joining the photovoltaic energy of solar power generation with the charging of PEV, it is conceivable to amplify the advantages and limit the expenses, through high entrances of the two penetrations in the power part, what decreases outflows from the EV charging at peak time. The first one gives power during top noontime in summer, diminishing the requirement for extra generation limit. The second one retains vitality from photovoltaic plants that would be wasted because of low power demand in the spring time. Numerical construction for unit commitment problem considering the impact of $\mathrm{EVs} / \mathrm{BEVS} / \mathrm{PEVs} / \mathrm{HEVs}$ are given below;

\section{Maximum and Minimum Operating Limits of}

\section{Generators:}

All generating units have its individual minimum/maximum electric power generation limit, below and outside which will cannot produce and this is known as maximum and minimum power limits, which is mathematically written as:

$$
P_{i(\min )} \leq P_{h i} \leq P_{i(\max )} \quad(i=1,2, \ldots, N G ; \quad h=1,2, \ldots, H)
$$

In power system the constraint including power balance or load balance is more important parameter consist of summation of whole committed generating unit at hth time span must be larger than or equivalent to the power demand for the particular time span ' $h$ '

Power Balance Constraints: $\sum_{i=1}^{N G} P_{h i} U_{h i}=D_{h}$

In recent years, renewable energy sources have been one of the quickly developing vitality change frameworks. Renewable energy sources assumes significant job in satisfying the electricity demand and environmental protection. The deep penetration of wind and sun based force is a basic part of things to future power grid. In any case, the irregularity and stochasticity of these renewable resources carry significant difficulties to the dependable and financial activity of intensity frameworks. Considering Renewable Energy Sources (RES), the power through RES are taken into consideration.

$$
\sum_{i=1}^{N G} P_{h i} U_{h i}-P_{h}^{\text {Re newable }}=D_{h}
$$

To achieve the unit commitment generation scheduling,

power losses must be taken into account,

$$
\sum_{i=1}^{N G} P_{h i} U_{h i}=D_{h}+P_{h L}
$$

Electric power generation in power stations go through huge and complex systems like transformers, overhead lines, links and other gear and reaches toward the end users. Transmission and Distribution losses are the amounts that are not paid for by clients. Considering Power Losses considering Renewable Energy Sources, the equation is given below, 


$$
\sum_{i=1}^{N G} P_{h i} U_{h i}-P_{h}^{\text {Re newable }}=D_{h}+P_{h L}
$$

By using power balance equation, the power output for

Rth reference unit can be written as:

$$
P_{h R}=D_{h}+P_{h L}-\sum_{\substack{i=1 \\ i \neq R}}^{N G} P_{h i}
$$

By using power balance equation and considering Renewable Energy Sources, the power output for $\mathrm{R}^{\text {th }}$ reference unit can be written as:

$$
P_{h R}=D_{h}+P_{h L}-\left(\sum_{\substack{i=1 \\ i \neq R}}^{N G} P_{h i}+P_{h}^{\text {Renewable }}\right)
$$

The extra capability of power generation is recognized as Spinning Reserve which is exactly represented as:

Spinning Reserve

Constraints:

$$
\sum_{i=1}^{N G} P_{i(\max )} U_{h i} \geq D_{h}+R_{h}
$$

Case-1: During Charging of EVs/BEVs:

The vehicle electrification will significantly affect the power grid because of the expansion in power utilization. It is essential to perform intelligent planning for charging and discharging of electric vehicles (EVs). In any case, there are two significant difficulties in the scheduling issue. To start with, it is trying to discover the all-around ideal scheduling arrangement which can limit the complete expense. It is hard to locate an appropriated scheduling plan which can deal with an enormous population and the arbitrary appearances of the EVs. In power system the constraint including power balance or load balance is more important parameter consist of summation of whole committed generating unit at hth time span must be larger than or equivalent to the power demand for the particular time span ' $h$ '. The power balance constraints during charging of EVs and considering renewable energy sources is given below.

Power Balance Constraints:

$\sum_{i=1}^{N G} P_{h i} U_{h i}=D_{h}+D_{h}^{E V S / B E V s}$

Considering Renewable Energy Sources, the power balance equation is given below, $\sum_{i=1}^{N G} P_{h i} U_{h i}-P_{h}^{\text {Re newable }}=D_{h}+D_{h}^{E V S / B E V s}$

While charging or discharging electric vehicles, power loss happen. Another utilization case for electric vehicles, grid services has as of recently started business activity. Considering Power Losses during Charging of $\mathrm{EV} / \mathrm{BEV}$ s including renewable energy sources, the equation is given below.
$\sum_{i=1}^{N G} P_{h i} U_{h i}=D_{h}+P_{h L}+D_{h}^{E V S / B E V S}$

Considering Renewable Energy Sources during Charging of EVs/BEVs:

$\sum_{i=1}^{N G} P_{h i} U_{h i}-P_{h}^{\text {Re newable }}=D_{h}+P_{h L}+D_{h}^{\text {EVs/BEVs }}$

By using power balance equation, the power output for $\mathrm{R}^{\text {th }}$ reference:

$P_{h R}=D_{h}+P_{h L}-\left(\sum_{\substack{i=1 \\ i \neq R}}^{N G} P_{h i}-D_{h}^{E V S / B E V S}\right)$

By using power balance equation considering Renewable Energy Sources, the power output for Rth reference unit can be written as:

$P_{h R}=D_{h}+P_{h L}-\left(\sum_{\substack{i=1 \\ i \neq R}}^{N G} P_{h i}+P_{h}^{\text {Renewable }}-D_{h}^{E V s / B E V s}\right)$

Reliability of the system can be considered as facility of extra capability of power generation that is more important to deed instantly when failure is occurred due to sudden change in load demand for such power generating unit which is already running.

Spinning Reserve Constraints:

$$
\sum_{i=1}^{N G} P_{i(\max )} U_{h i} \geq D_{h}+D_{h}^{E V S / B E V s}+R_{h}
$$

Spinning Reserve Constraints considering Renewable Energy Sources:

$$
\sum_{i=1}^{N G} P_{i(\max )} U_{h i}-P_{h}^{\text {Re newable }} \geq D_{h}+D_{h}^{\text {EVs/BEVS }}+R_{h}
$$

Case-2: During Discharging of EVs/BEVs:

The plug-in electric vehicles (PEVs) represents the alternatives of the outflow of poisons from vehicles controlled by petroleum derivatives. The plug-in electric vehicle charging is recurrent, variable and to some degree of unpredictable, as it goes about as a load to the power grid. Power Balance Constraints during discharging:

$$
\sum_{i=1}^{N G} P_{h i} U_{h i}=D_{h}-D_{h}^{E V S / B E V s}
$$

Power Balance Constraints considering Renewable Energy Sources and EVs/BEVs:

$$
\sum_{i=1}^{N G} P_{h i} U_{h i}-P_{h}^{\text {Re newable }}=D_{h}+P_{h L}-D_{h}^{E V S / B E V S}
$$

In spite of the charging need, a PEV can likewise be utilized to offer subordinate types of assistance to the power system, pointing the grid benefit. Such vehicles are truncated as V2G, from vehicle-to-grid, and, as significant models, can give guideline, renewable sources support and distribution losses minimization. Considering Power Losses during discharging of electric vehicle is given below.

$$
\sum_{i=1}^{N G} P_{h i} U_{h i}=D_{h}+P_{h L}-D_{h}^{E V S / B E V S}
$$

Power Balance Constraint considering Transmission Losses and Renewable Energy Sources: 


$$
\sum_{i=1}^{N G} P_{h i} U_{h i}-P_{h}^{\text {Re newable }}=D_{h}-D_{h}^{E V S / B E V s}
$$

By using power balance equation, the power output for $\mathrm{R}^{\text {th }}$ reference:

$$
P_{h R}=D_{h}+P_{h L}-\left(\sum_{\substack{i=1 \\ i \neq R}}^{N G} P_{h i}+D_{h}^{E V s / B E V s}\right)
$$

By using power balance equation considering Renewable Energy Sources, the power output for Rth reference unit can be written as:

$$
P_{h R}=D_{h}+P_{h L}-\left(\sum_{\substack{i=1 \\ i \neq R}}^{N G} P_{h i}+P_{h}^{\text {Renewable }}+D_{h}^{E V S / B E V s}\right)
$$

Reliability of the system can be considered as facility of extra capability of power generation that is more important to deed instantly when failure is occurred due to sudden change in load demand for such power generating unit which is already running.

Spinning Reserve Constraints:

$$
\sum_{i=1}^{N G} P_{i(\max )} U_{h i} \geq D_{h}-D_{h}^{E V S / B E V S}+R_{h}
$$

Spinning Reserve Constraints considering Renewable Energy Sources and EVs/BEVs

$$
\sum_{i=1}^{N G} P_{i(\max )} U_{h i}-P_{h}^{\text {Re newable }} \geq D_{h}-D_{h}^{\text {EVs/BEVS }}+R_{h}
$$

\section{Results \& Discussions}

The recently developed Intensify Harris Hawks Optimizer developed by corresponding author has been applied to solve the proposed research problem. The mathematical formulation and Pseudo code of IHHO algorithm can be found in [24]. Generation Schedule of Committed Units for 10-Unit Test System at 5\% and $10 \%$ Spinning Reserve are shown in fig. 3 and fig. 4. This system has been verified for 24-hour electric power demand outline at various spinning reserve capability such as $5 \%$ and $10 \%$ including Charging and Discharging Behaviour of EVs and considering renewable energy sources in the season of winter and summer.

Table 2. Total overall generation cost for 10 unit test system including Charging and Discharging Behaviour of EVs

\begin{tabular}{|c|c|c|}
\hline Generating Units & $\begin{array}{c}\text { Generation Cost } \\
\text { without the effect } \\
\text { of EVs (\$) }\end{array}$ & $\begin{array}{c}\text { Generation Cost } \\
\text { with the effect of } \\
\text { EVs (\$) }\end{array}$ \\
\hline 10 -unit (5\% SR) & 557533.12 & 552325 \\
\hline 10 -unit (10\% SR) & 563937.6875 & 559256.7 \\
\hline
\end{tabular}

Table 3. Total overall generation cost for 10 unit test system considering Renewable Energy Sources in winter and summer

\begin{tabular}{|c|c|c|}
\hline Generating Units & $\begin{array}{c}\text { Generation Cost } \\
\text { in Winter }\end{array}$ & $\begin{array}{c}\text { Generation Cost } \\
\text { in Summer }\end{array}$ \\
\hline 10 -unit $(5 \% \mathrm{SR})$ & 536200 & 529980 \\
\hline 10 -unit $(10 \% \mathrm{SR})$ & 539110 & 534050 \\
\hline
\end{tabular}

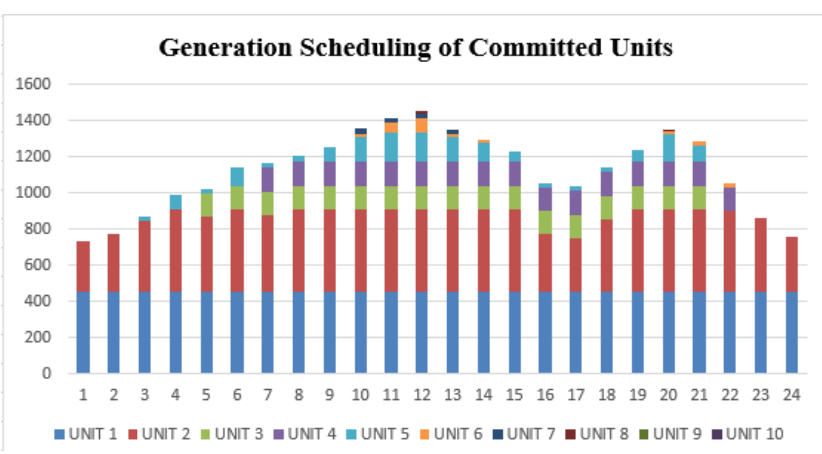

Fig. 3. Generation Schedule of Committed Units for 10-Unit Test System at 5\% Spinning Reserve considering Charging and Discharging Behaviour of EVs

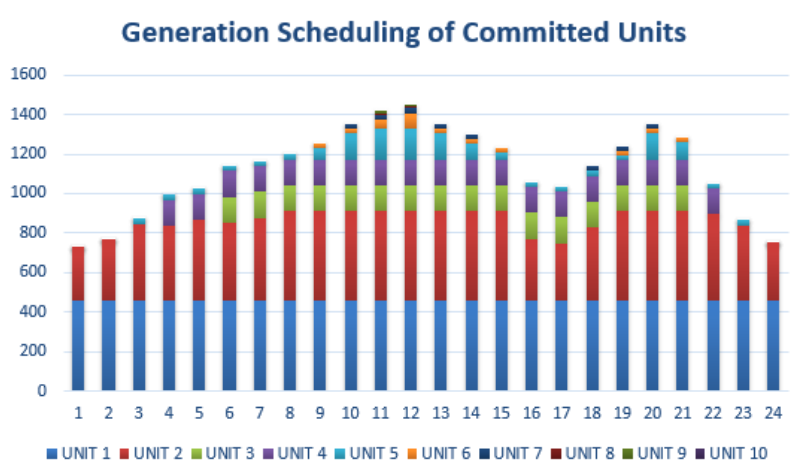

Fig. 4. Generation Schedule of Committed Units for 10-Unit Test System at 10\% Spinning Reserve considering Charging and Discharging Behaviour of EVs

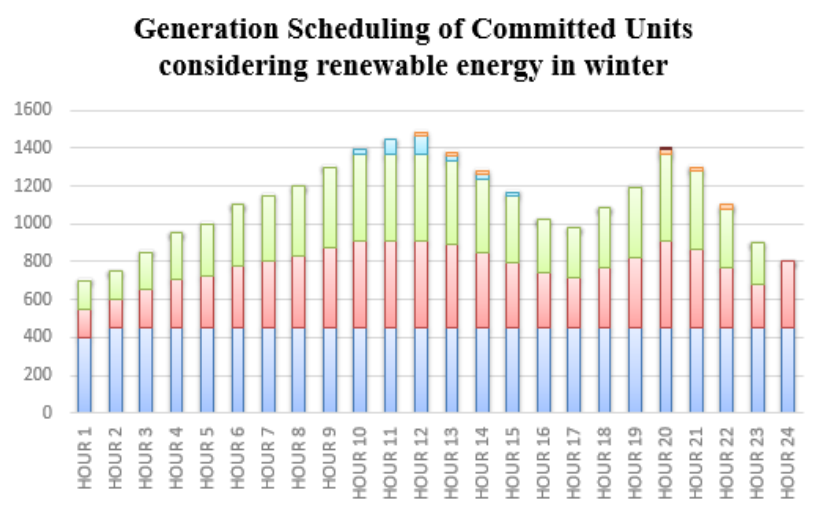

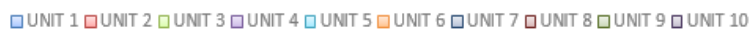
Fig. 5. Generation Schedule of Committed Units for 10-Unit Test System at 5\% Spinning Reserve considering Renewable Energy Sources in winter

Generation Scheduling of Committed Units Considering Renewable Energy in Winter

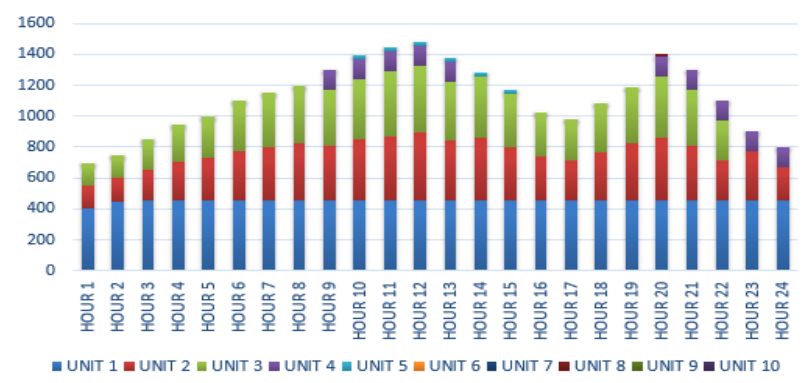

Fig. 6. Generation Schedule of Committed Units for 10-Unit Test System at 10\% Spinning Reserve considering Renewable Energy Sources in winter 


\section{Generation Scheduling of Committed Units Considering Renewable Energy in Summer}

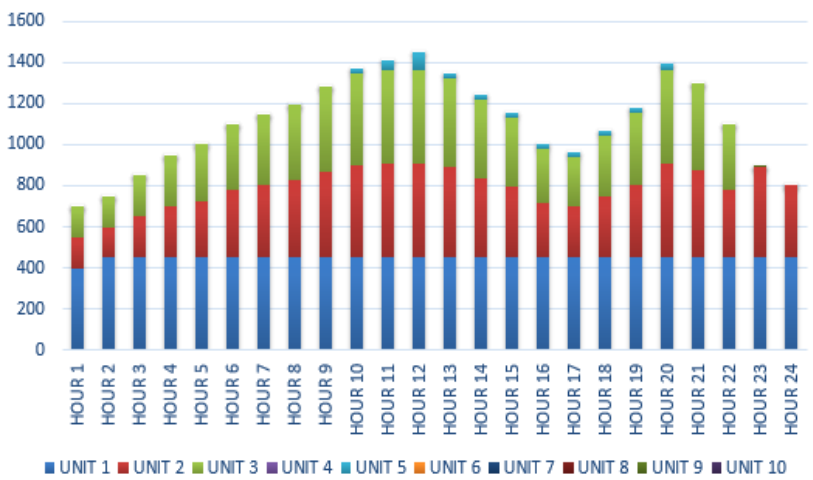

Fig. 7. Generation Schedule of Committed Units for 10-Unit Test System at 5\% Spinning Reserve considering Renewable Energy Sources in summer

Generation Scheduling of Committed Units Considering Renewable Energy in Summer

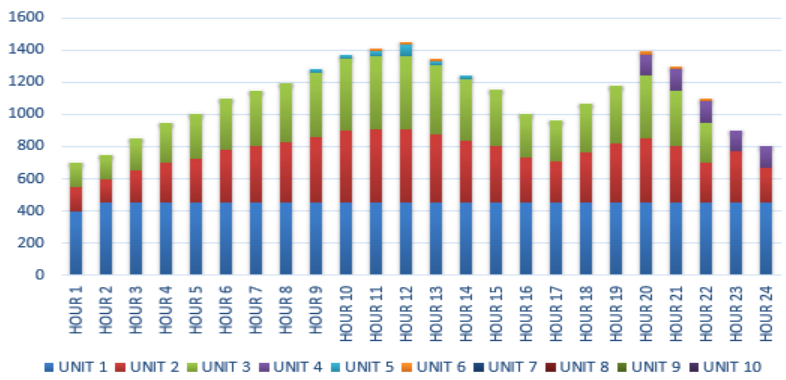

Fig. 8. Generation Schedule of Committed Units for 10-Unit Test System at 10\% Spinning Reserve considering Renewable Energy Sources in summer

\section{CONCLUSIONS}

In the suggested research work, the authors has successfully presented mathematical formulation of PBUCP considering battery electric vehicles, plug-in electric vehicles and renewable energy sources (solar and wind power), which is one of the challenging problems in power system operation control and planning. PBUCP of electric power system is considered. The proposed numerical construction of PBUCP will be helpful for researchers, who are working in this kind of problems with electric vehicles (EVs) i.e. battery electric vehicles, Renewable energy sources (RES) and plug-in hybrid electric vehicle as one of the research objectives.

\section{References}

1. J. S. Dhaliwal and J. S. Dhillon, "Profit based unit commitment using memetic binary differential evolution algorithm," Appl. Soft Comput. J., p. $105502,2019$.

2. A. Nandi and V. K. Kamboj, "Hgwo-RES : A Hybrid Algorithm with Improved Exploitation Capability For Profit Based Unit Commitment Problem," no. 16, pp. 4731-4741, 2019.

3. S. Reddy K, L. K. Panwar, B. K. Panigrahi, R. Kumar, and A. Alsumaiti, "Binary grey wolf optimizer models for profit based unit commitment of price-taking GENCO in electricity market," Swarm Evol. Comput., 2018.

4. K. S. Reddy, L. Kumar, R. Kumar, and B. K. Panigrahi, "Electrical Power and Energy Systems Binary fireworks algorithm for profit based unit commitment ( PBUC ) problem," Int. J. Electr. POWER ENERGY Syst., vol. 83, pp. 270-282, 2016.

5. S. R. K, L. K. Panwar, B. K. Panigrahi, R. Kumar, and A. Alsumaiti, "SC," Swarm Evol. Comput. BASE DATA, 2018.

6. A. Shukla, V. N. Lal, S. Members, S. N. Singh, and S. Member, "Profit-Based Unit Commitment Problem Using PSO with Modified Dynamic Programming," pp. 1-6, 2015.

7. K. Venkatesan, G. Selvakumar, and C. C. A. Rajan, "EP BASED PSO METHOD FOR SOLVING PROFIT BASED MULTI AREA UNIT COMMITMENT PROBLEM," vol. 10, no. 4, pp. 442-460, 2015.

8. G. Morales-españa, A. Ramos, and C. Gentile, "Tight MIP formulations of the power-based unit commitment problem," OR Spectr., vol. 37, no. 4, pp. 929-950, 2015.

9. S. Maghsudlu and S. Mohammadi, "Optimal scheduled unit commitment considering suitable power of electric vehicle and Optimal scheduled unit commitment considering suitable power of electric vehicle and photovoltaic uncertainty," vol. 043705, 2018.

10. M. Shahbazitabar and H. Abdi, "AC," Energy, 2018.

11. F. Rahiman, P. Mohd, F. Othman, and S. Ottukuloth, "Power Station Scheduling with Energy Storage," J. Inst. Eng. Ser. B, 2018.

12. Yogeswara Reddy B, Srinivas Rao J, Suresh Kumar T, Nagarjuna A, Int. J. of Inn. Tech. and Exp. Engg., vol.8, no.11, pp:1194-1198, 2019

13. H. Quan, D. Srinivasan, and A. Khosravi, "Integration of renewable generation uncertainties into stochastic unit commitment considering reserve and risk: A comparative study," Energy, vol. 103, pp. 735-745, 2016.

14. S. Y. Abujarad, M. W. Mustafa, and J. J. Jamian, “crossmark," Renew. Sustain. Energy Rev., vol. 70, no. November 2016, pp. 215-223, 2017.

15. K. Selvakumar, B. Vignesh, C. S. Boopathi, and T. Kannan, "Thermal Unit Commitment Strategy Integrated with Solar Energy System," vol. 11, no. 9, pp. 6856-6860, 2016.

16. E. A. Jasmin, G. E. College, and G. E. College, “A FUNCTION APPROXIMATION APPROACH TO REINFORCEMENT LEARNING FOR SOLVING UNIT COMMITMENT PROBLEM WITH PHOTO VOLTAIC SOURCES."

17. H. Quan, D. Srinivasan, A. M. Khambadkone, and A. Khosravi, "A computational framework for uncertainty integration in stochastic unit commitment with intermittent renewable energy sources," Appl. Energy, vol. 152, pp. 71-82, 2015.

18. K. Chandrasekaran and S. P. Simon, "Binary / Real Coded Particle Swarm Optimization for Unit 
Commitment Problem," no. 3.

19. T. Senjyu, S. Chakraborty, A. Y. Saber, H. Toyama, and A. Yona, "Thermal Unit Commitment Strategy with Solar and Wind Energy Systems Using Genetic Algorithm Operated Particle Swarm Optimization," no. PECon 08, pp. 866-871, 2008.

20. S. Saurabh and M. Ahmed, Optimization Method for Unit Commitment in High-Level Wind Generation and Solar Power. Springer Singapore.

21. A. Safari and H. Shahsavari, "Frequencyconstrained unit commitment problem with considering dynamic ramp rate limits in the presence of wind power generation," Neural Comput. Appl., vol. 0123456789, 2018.

22. M. P. Varghese and A. Amudha, "Artificial Bee Colony and Cuckoo Search Algorithm for Cost Estimation with Wind Power Energy," pp. 1-8.

23. [M. Govardhan, R. Roy, M. Govardhan, and R. Roy, "Electric Power Components and Systems Comparative Analysis of Economic Viability with Distributed Energy Resources on Unit Commitment Comparative Analysis of Economic Viability with Distributed Energy Resources on Unit Commitment," vol. 5008, no. August, 2016.

24. V. K. Kamboj, A. Nandi, A. Bhadoria, and S. Sehgal, "An intensify Harris Hawks optimizer for numerical and engineering optimization problems," Appl. Soft Comput., p. 106018, 2019. 